\title{
A CONCEPÇÃO DE FORMAÇÃO DE PROFESSORES PRESENTE NAS TESES SOBRE O CURRÍCULO DE PEDAGOGIA NO BRASIL: UMA ANÁLISE CRÍTICA ${ }^{1}$
}

Carolina Nosella Gama²

Cláudio de Lira Santos Júnior ${ }^{3}$

\section{RESUMO}

Este artigo é parte constitutiva da pesquisa de mestrado intitulada Contribuição à crítica da produção do conhecimento sobre o currículo de pedagogia no Brasil: uma análise das teses (1987-2010). O levantamento das produções foi realizado no banco de teses e dissertações da Coordenação de Aperfeiçoamento de Pessoal de Nível Superior (CAPES) e na Biblioteca Digital Brasileira de Teses e Dissertações (BDTD), no período de 1987 a 2010, utilizando os termos de busca 'currículo de pedagogia' e 'currículo do curso de pedagogia'. Esta investigação permitiu-nos identificar as concepções de formação de professores hegemônicas nos estudos sobre o currículo de pedagogia, em particular, e sobre a formação de professores, no geral. Nosso objetivo é expor a análise acerca das concepções de formação de professores hegemônicas presentes nas teses sobre currículo de pedagogia no Brasil, tendo em vista a relação das mesmas com o modo de produção da existência, bem como as possibilidades contra-hegemônicas expressas nesta relação. A análise demonstrou que hegemonicamente as teses fundamentam-se numa visão idealista de homem, centrando a discussão do currículo na subjetividade. As explicações teóricas densas são substituídas por descrições fenomênicas e interpretações consensuais da realidade. Discute-se o currículo sem considerar que a sua alteração vincula-se a luta pela superação da realidade que o determina, o que não contribui para o enfrentamento dos problemas educacionais do nosso país.

Palavras-chave: formação de professores; modo de produção; teses sobre o currículo de pedagogia.

\section{THE PROPOSITION OF TEACHER EDUCATION IN THE THESES ABOUT THE PEDAGOGY CURRICULUM IN BRAZIL: A CRITICAL ANALYSIS}

\section{ABSTRACT}

This article is a constitutive part of the Master thesis entitled Contribution to the Critique of knowledge production about the curriculum pedagogy in Brazil : an analysis of theses ( 1987-2010 ). The search was conducted on database of theses and dissertations of the Coordination of Improvement of Higher Education Personnel ( CAPES ) and the Brazilian Digital Library of Theses and Dissertations ( BDTD ) in the period 1987-2010, using the search terms ' curriculum pedagogy 'and' curriculum of pedagogy ' . This research allowed us to identify the hegemonic conceptions of teachers formation in thesis about the curriculum pedagogy, in particular, and on the education of teachers in general. Our goal is to expose the review about the hegemonic conceptions of teachers formation present in theses of pedagogy curriculum in Brazil, considering the relationship thereof with the production mode of existence, as well as counter-hegemonic possibilities expressed in this regard. The analysis showed that the hegemonic theories are based on a idealistic view of man , focusing the discussion on subjectivity of the curriculum. The dense theoretical explanations are replaced by phenomenological descriptions and consensual interpretations of reality. Discuss the curriculum without considering that your change is linked to the struggle to overcome the reality that determines which does not contribute to addressing the educational problems of our country.

Keywords: teacher education; mode of production; theses about the pedagogy curriculum.

Revista HISTEDBR On-line, Campinas, $n^{\circ}$ 59, p.166-175, out2014-ISSN: 1676-2584 


\section{Introdução}

Este artigo é parte constitutiva da nossa pesquisa de mestrado intitulada Contribuição à crítica da produção do conhecimento sobre o currículo de pedagogia no Brasil: uma análise das teses (1987-2010) ${ }^{4}$, na qual analisamos 14 teses de doutorado, cujos resultados fornecem a base deste texto. Esta investigação permitiu-nos identificar as concepções de formação de professores hegemônicas nos estudos sobre o currículo de pedagogia, em particular, e sobre a formação de professores, no geral. Nosso objetivo é expor a análise acerca das concepções sobre a formação de professores hegemônicas nas teses sobre currículo de pedagogia no Brasil, e verificar a relação das mesmas com o modo de produção da existência, indagando sobre as possibilidades contra-hegemônicas expressas nesta relação.

Partimos da explicitação dos pressupostos teórico-metodológicos adotados, para na sequência, apresentarmos o conteúdo da análise, e por fim uma síntese indicativa de possibilidades investigativas acerca da formação de professores, em especial de pedagogos, com base na categoria modo de produção. Para análise tomamos como parâmetro teóricometodológico a crítica em Marx a partir da elaboração feita por Enguita (1985) referente às características de uma crítica marxista da educação. De acordo com o autor a crítica não deve perder de vista a totalidade histórica e social. Para tanto, a produção do conhecimento objeto do estudo foi analisada como produto histórico, ou seja, em relação ao modo de produção da existência e seu estágio de desenvolvimento, bem como as relações sociais que dele decorrem.

Vários estudos já pautaram os problemas enfrentados nos cursos de pedagogia no Brasil, e sabemos que os mesmos vêm acompanhando esta área desde sua origem. Saviani (2008a), por exemplo, demonstra como historicamente veio se dando a constituição do espaço acadêmico da pedagogia no Brasil e como este processo está relacionado ao problema surgido a partir do século XIX, da necessidade de universalizar a instrução elementar que conduziu à necessidade de formação de professores em grande escala. Freitas (1993; 2002); Brzezinski (1996); Silva (2003), entre outros também pautam esta discussão, principalmente no que cerne a cisão entre formação teórica e formação prática na formação de pedagogos, cuja explicação tem base na divisão social do trabalho que marca a formação unilateral dos homens, e que por isso não será superada da noite para o dia 5 .

No âmbito da educação, advém desta compreensão o fato de explicarmos a relação entre projeto histórico, teoria do conhecimento, teoria educacional, teoria pedagógica, trabalho educativo e metodologias específicas, uma vez que a educação e seus desdobramentos teórico-práticos não estão deslocados do mais geral, que é o modo de produção capitalista. Sobre isto, Freitas (1995, p. 93), explica:

A teoria educacional formula uma concepção de educação apoiada em um projeto histórico e discute as relações entre educação e sociedade em seu desenvolvimento; que tipo de homem se quer formar; os fins da educação, entre outros aspectos. Uma teoria pedagógica, por oposição, trata do ‘trabalho pedagógico', formulando princípios norteadores.

Consideramos que o homem não nasce homem, mas se torna homem à medida que acessa e se apropria, por meio de processos educativos, aquilo que de mais avançado a humanidade produziu no decorrer da história. Assim, corroborando com Saviani (2008b), destacamos que a importância política da educação reside na sua função de socialização do conhecimento, sendo necessário defendermos intransigentemente a recuperação do papel da escola que: 
[...] tem uma função especificamente educativa, propriamente pedagógica, ligada à questão do conhecimento; é preciso, pois resgatar a importância da escola e reorganizar o trabalho educativo, levando em conta o problema do saber sistematizado, a partir do qual se define a especificidade da educação escolar. (SAVIANI, 2008b, p. 98)

Deste modo, considerando que o currículo é "“[...] o projeto de uma prática concreta, real, histórica, resultado das relações sociais, políticas e pedagógicas, que se expressam na organização do trabalho pedagógico, no trato com conhecimentos vinculados à formação do ser humano, sob a responsabilidade da escola.", (TAFFAREL, et.al., 2009, p.185, no prelo); entendendo que a natureza humana não é dada, mas produzida pelos próprios homens a partir do trabalho, defendemos o trabalho educativo como "[...] o ato de produzir, direta e intencionalmente, em cada indivíduo singular, a humanidade que é produzida histórica e coletivamente pelo conjunto dos homens." (SAVIANI, 2008b, p.7).

Reconhecemos que o problema do sistema educacional brasileiro não se limita à problemática da formação do pedagogo, mas esta contém em si as determinações mais gerais do modo de produção capitalista, que vem desqualificando os trabalhadores em diversos aspectos, dentre eles, por meio da negação do acesso ao conhecimento.

Tomamos a categoria modo de produção como categoria mediadora de todas as outras, visto que, é o modo como os homens produzem sua existência que move a história. Além disto, esta categoria carrega o particular e o universal, ou seja: i) o grau de desenvolvimento das forças produtivas (estrutura que corresponde ao trabalho humano, terras e técnica) e ii) o grau de desenvolvimento das relações de produção que acompanha o desenvolvimento das forças produtivas.

Na contramão da pós-modernidade, empreendemos um terceiro movimento: a defesa da análise da produção do conhecimento orientada por uma macroteoria explicativa; a defesa de que esta teoria macroexplicativa é a concepção materialista e dialética da história, portanto, a defesa da história em contraposição às particularidades, à cultura e à memória; a defesa do materialismo, da ciência e da razão, em contraposição ao idealismo, ao misticismo e ao irracionalismo. (PEIXOTO, 2007, p. 301)

É nesta direção que nosso estudo se colocou, reconhecendo a necessidade de não nos descolarmos da categoria modo de produção, visto que, a possibilidade de realizarmos análises - radicais, na totalidade e de conjunto - aumenta à medida que guiamos nossos estudos tendo em vista esta categoria central. Significa dizer, que para compreendermos as determinações históricas da produção do conhecimento faz-se necessário questionarmos sobre as transformações ocorridas no modo de produção da existência. Explicitado isto, passemos a análise das concepções de formação de professores presentes nas teses sobre o currículo de pedagogia no Brasil.

\section{Crítica às concepções hegemônicas de formação de professores nas teses sobre currículo de pedagogia no Brasil}

O levantamento da concepção de trabalho educativo presente nas teses analisadas demonstrou que: $43 \%$ delas defendem que a atividade do professor deve pautar-se na ação reflexiva do mesmo sobre sua prática cotidiana; $14 \%$ desvinculam o trabalho educativo do ato de ensinar; $14 \%$ fazem menção ao trabalho educativo, enquanto espaço de disputa, mas 
não expõem a concepção que defendem; 7\% vincula o trabalho educativo ao processo de ensino (sendo pautado na atividade, reflexão, pesquisa e sistematização das ações), porém ao tratar da escola defende a secundarização do ensino e do trato com o conhecimento objetivo; $7 \%$ não explica o que é o trabalho do professor, nem expõe que concepção defende, e $14 \%$ vinculam o trabalho pedagógico ao processo de ensino, que envolve objetivos, finalidades e conhecimentos.

A análise destas concepções demonstra que a negação da universalidade da cultura humana e da objetividade do conhecimento apresenta-se, em maior ou menor grau, em doze $(85,71 \%)$ das teses analisadas. Quando esta regularidade não se expressa de forma explícita através da concepção de trabalho educativo, ela apresenta-se por meio das demais categorias investigadas.

Duarte (2010) analisou a desvalorização do saber teórico presente nos estudos sobre a formação de professores a partir da década de 1990 no Brasil. O autor demonstra que a difusão do construtivismo, da pedagogia do professor reflexivo e da epistemologia da prática faz parte do ideário neoliberal e pós-moderno. Ao criticar as ideias defendidas por alguns autores protagonistas destes estudos, dentre os quais - Pérez Gómez, Tardif, Perrenoud e Schön -, Duarte destaca que os mesmos têm em comum a promoção do relativismo e do subjetivismo, marcas do espírito anticientífico da epistemologia pós-moderna. Explica que para este ideário não existe uma realidade objetiva passível de ser conhecida, o que o coloca na defesa do pragmatismo, tipicamente neoliberal. Conforme Duarte (2010, p. 21):

[...] pós-modernismo e neoliberalismo formam duas faces de um mesmo universo ideológico, ainda que muitos autores pós-modernos se consideram "de esquerda" e vejam a si mesmos como opositores do neoliberalismo. Ambos, o pragmatismo neoliberal e o ceticismo epistemológico pósmoderno, estão unidos na veneração da subjetividade imersa no cotidiano alienado da sociedade capitalista contemporânea.

Ao criticar as concepções de conhecimento tácito e conhecimento escolar que fundamentam a proposta de formação do professor reflexivo, Duarte (2010) explica que as implicações desta concepção para a formação de professores é que ao se atribuir um caráter negativo ao saber escolar, necessita-se defender uma pedagogia que não se baseie nele. Nesta perspectiva, "[...] o professor reflexivo seria aquele que adota uma pedagogia não pautada no saber escolar e concentra sua ação nas 'representações figurativas' contidas no conhecimento-na-ação dos alunos (o conhecimento tácito) [...]”, (ibid, p. 28). Deste modo, a ação pedagógica que faz a criança passar do conhecimento cotidiano ao conhecimento escolar não é considerada um progresso, por isso o caráter privilegiado tradicionalmente atribuído a escola é criticado. Assim como entendem não haver progresso na passagem do saber cotidiano do aluno ao saber escolar, também não há progresso na passagem do saber prático do professor ao saber científico e filosófico sobre educação. Assim, a "[...] formação de professores deveria, em vez de concentrar-se no domínio de teorias científicas, voltar-se para o saber experiencial do professor [...]”, (ibid, p. 29). Em síntese:

Nesta linha, seria então necessário mudar: 1) a concepção de conhecimento, passando a valorização do conhecimento escolar à valorização do conhecimento tácito, cotidiano, não científico; 2) a pedagogia, passando de uma pedagogia centrada na transmissão do saber escolar para uma centrada na atenção aos processos pelos quais os alunos constroem seu conhecimento; 3) a formação de professores, passando de uma formação centrada no saber teórico, científico, acadêmico, para uma centrada na prática reflexiva, na reflexão-na-ação. Nesta perspectiva, o lema 'aprender 
fazendo' da pedagogia escolanovista de inspiração deweyana deveria ser adotado tanto em relação à educação das crianças e adolescentes como no que diz respeito à formação profissional, incluída a formação de professores (ibid, p. 30)

Pautando-se numa concepção negativa sobre o ato de ensinar, negando a tarefa do professor e a função prioritária da escola na transmissão do conhecimento escolar, as teses discutem o currículo de pedagogia apartado da realidade concreta que o determina e na qual o pedagogo irá atuar. Ou seja, a escola no bojo da realidade educacional brasileira que possui um déficit enorme no que diz respeito à formação da classe trabalhadora, bem como a relação disto com a crise estrutural do capital e seu processo desumanizador. Como desdobramento desta negação da realidade, centra-se a discussão sobre o currículo de pedagogia na subjetividade, no sujeito e seu conhecimento tácito, o que leva ao silenciamento das necessidades e fatos concretos que precisam ser enfrentados, como por exemplo, o desmantelamento da educação, da escola pública e o rebaixamento da formação de professores.

Observemos que não há perspectiva de ação coletiva. Quando a ação transformadora é apontada, ela restringe-se a ação do sujeito sobre sua própria prática e não se vincula as necessidades históricas mais gerais, como a luta pela defesa de uma formação humana omnilateral, por exemplo. Ao ignorar-se a explicação ontológica acerca da formação da universalidade do gênero humano e da cultura, ignora-se a necessidade e a possibilidade da formação omnilateral e da superação da estrutura de classes burguesa e da divisão social e técnica do trabalho que separa e aliena o trabalhador dos meios, processos e resultados da produção, condenando burguesia e proletariado à formação unilateral.

Conforme apontamos anteriormente, como antítese a concepção de formação hegemônica, temos duas teses $(14 \%)$ que vinculam o trabalho pedagógico ao processo de ensino, que envolve objetivos, finalidades e conhecimentos. Estas teses explicam a relação entre o modo de produção capitalista e a formação do pedagogo, realizando uma crítica à sociedade de classes e apontando a necessidade de sua superação, defendem explicitamente o projeto histórico socialista, ligado à formação omnilateral. O projeto histórico defendido vincula-se à concepção de homem/formação humana que entende o homem como resultado do trabalho. Estas teses pautam a discussão sobre o currículo de formação de professores a partir de sua base material, ou seja, explicitam os nexos entre os problemas educacionais e o modo de produção da vida. Vinculam a superação dos problemas educacionais ao desenvolvimento de proposições curriculares que contribuam com a formação de pedagogos comprometidos com a luta da classe trabalhadora pela superação do capital.

Ao partir de uma concepção marxista de homem/formação humana, que entende a história como fundamental para as elaborações sobre o currículo, apontam a possibilidade intencional da sua alteração tendo em vista um projeto histórico e formativo para além do capital. Entendendo a atividade vital humana (o trabalho) enquanto uma possibilidade universal de riqueza, reconhecem que no trabalhador está contida também uma possibilidade humana universal, (MANACORDA, 2007). Ao fazê-lo assumem o papel de dar substância concreta a bandeira de luta da classe trabalhadora, lutando para garantir aos trabalhadores um ensino da melhor qualidade possível nas condições históricas atuais, de modo a evitar que esta bandeira seja apropriada e articulada com os interesses dominantes, (SAVIANI, 1987).

Diante do exposto, é necessário indagarmos sobre os nexos entre o quadro encontrado nas teses e o modo de produção da existência. Ao examinarmos o período em que foram defendidas tais teses, verificamos que as mesmas situam-se entre os anos de 1993 e 2010, sendo que a partir de 2004 há um aumento na frequência e na quantidade de 
trabalhos acerca do tema buscado. O período coincide com o pós LDB (Lei nº 9394/96), que estabelece a exigência de elevação do nível de formação de professores para as séries iniciais, que é caracterizado pelo grande debate que se travou acerca das políticas de formação de professores. No que diz respeito à definição de políticas públicas para a formação de professores, estas se expressam de maneira mais visível nos Referenciais Curriculares para Formação de Professores (1999), no Parecer no 115/99 que criou os institutos superiores de educação e nas Diretrizes Curriculares para a Formação Inicial de Professores para a Educação Básica em Nível Superior (2001).

Evidenciam, portanto, o processo de flexibilização curricular em curso tendo em vista a adequação do ensino superior às novas demandas oriundas do processo de reestruturação produtiva por que passam os diferentes países, objetivando adequar os currículos aos novos perfis profissionais resultantes dessas modificações. (FREITAS, 2002, p.137)

Freitas (2002) cita Catani (et al., 2000) que alerta para os riscos do ideário da flexibilização curricular, afirmando que tais “dinâmicas certamente 'naturalizam' o espaço universitário como campo de formação profissional em detrimento de processos mais amplos reduzindo, sobretudo, o papel das universidades".

É neste contexto histórico de disputa de projetos que se dá a elaboração das teses investigadas neste estudo. De um lado o movimento dos educadores pela formação e profissionalização do magistério, encampado, principalmente, pela ANFOPE, lutando pela defesa de concepções avançadas sobre a formação do professor, contra a degradação da profissão. E de outro lado, o processo de flexibilização curricular tendo em vista a adequação do ensino superior às novas demandas oriundas do processo de reestruturação produtiva, subordinado às orientações políticas neoliberais.

A acumulação flexível pautada no regime de encomenda-produção-entrega (just-intime) visa a flexibilização dos mercados e das relações de trabalho, bem como das barreiras comerciais, do controle da iniciativa privada pelo Estado. A flexibilização estatal provoca transformações, mais diretamente de âmbito político, como: políticas neoliberais, oposição ao Estado de bem-estar social; precarização dos serviços públicos; flexibilização de direitos; aumento da informalidade; desemprego estrutural; tercerização; subcontratos; precarização do trabalho; controle financeiro internacional; desregulamentação dos mercados e das relações de trabalho; fragmentação na composição da classe trabalhadora (entre os trabalhadores mais escolarizados com certa garantia de emprego, e os trabalhadores temporários, subcontratados, vinculados à economia informal); enfraquecimento dos sindicatos, (PINTO, 2007).

Revestida de ideais políticos bem convincentes e sedutores, como a dignidade e a liberdade individual, esta nova configuração das práticas político-econômicas, conhecida como neoliberalismo, associa-se à restauração do poder das elites econômicas, (HARVEY, 2008). Tanto que quando estes ideais entram em conflito com a reconstrução e sustentação da elite eles são abandonados ou distorcidos, e todas as formas de solidariedade social são dissolvidas em favor do individualismo, da propriedade privada, da responsabilidade individual (ibid, p.32). A luta pelo que nos diferencia é sobreposta a luta pelo que nos unifica.

Acompanhando as alterações no âmbito da produção, na área educacional desenvolvem-se proposições pedagógicas que visam formar o trabalhador necessário a sustentação do capital. Face à crise estrutural do desemprego e desenvolvimento desigual, a inserção e o ajuste dos países "não desenvolvidos" ou "em desenvolvimento" ao processo de globalização e na reestruturação produtiva, sob uma nova base científica e tecnológica, dependem da educação básica, de formação profissional, qualificação e requalificação, 
Frigotto (1998). Trata-se de uma formação que desenvolva habilidades básicas, produzindo competências para gestão da qualidade, para a produtividade e competitividade, e consequentemente, para a "empregabilidade". Trata-se, para o assalariado, de estar disponível para todas as mudanças.

No âmbito da formação de professores, a desqualificação do trabalhador necessária ao processo de reestruturação produtiva se expressa no rebaixamento dos cursos de formação.

Nos anos de 1990, a "década da educação", vivenciamos o aprofundamento das políticas neoliberais. $\mathrm{O}$ processo de ajuste estrutural, com $\mathrm{o}$ enxugamento dos recursos do Estado para a educação e para as políticas sociais, e a privatização criam novas formas de direcionamento dos recursos públicos: sua distribuição, centralização e focalização para as experiências que se adéquiem aos princípios das reformas sociais em curso. Configura-se o descompromisso do Estado para com o financiamento da educação para todos, em todos os níveis, revelando a subordinação do nosso país às exigências do Banco Mundial e à lógica do mercado. No âmbito das políticas de formação de professores mudanças significativas foram implementadas, objetivando a construção de um professor com habilidades e competências capazes de torná-lo a correia de transmissão, na escola e na sala de aula, das novas formas de laboralidade demandadas pelo nível de desenvolvimento do capitalismo na atualidade. (FREITAS, 2003, p. 1095).

Um balanço dos programas e cursos propostos pelo Ministério da Educação (MEC) para ampliar a formação de professores, realizado no XIV Encontro Nacional da ANFOPE em 2008, revela que embora estas ações representem uma importante iniciativa para a ampliação da formação destes profissionais, elas apresentam sérios problemas. Dentre estas ações destacam-se: a Universidade Aberta do Brasil (UAB), que propõe a implantação do ensino superior a distância para graduar professores em exercício; a expansão universitária através do Programa de Apoio a Planos de Reestruturação e Expansão das Universidades Federais (REUNI), que amplia vagas na universidade sem garantir as condições mínimas de manutenção das mesmas, entre outros. Diante da demanda nacional de ocupação de cargos docentes são propostas, a Comissão Especial do CNE sugere em relatório 'soluções estruturais e emergências', dentre elas:

Formação de professores em licenciaturas polivalentes; estruturar currículos envolvendo a formação pedagógica; instituir programas de incentivo às licenciaturas; criação de bolsas de incentivo à docência; critério de qualidade na formação de professores por educação a distancia; integração da educação básica ao ensino superior; incentivo ao professor universitário que se dedica à educação básica. Como soluções emergenciais, o relatório sugere: contratação de profissionais liberais como docentes; aproveitamento emergencial de alunos de licenciatura como docentes; bolsas de estudos para alunos carentes em instituições da rede privada; incentivo ao retardamento das aposentadorias dos professores; incentivo para professores aposentados retornarem à atividade docente; contratação de professores estrangeiros em determinadas disciplinas; uso complementar das tele-salas existentes. (BRZEZINSKI, 2011, p. 95)

Além das políticas educacionais de formação de professores serem fragmentadas, verifica-se um processo de aligeiramento das exigências nos processos de qualificação 
docente, bem como a redução de investimentos. Esta configuração responde ao modelo de expansão educacional implementado na década de 1990 caracteriza-se pela diversificação e flexibilização da oferta de cursos de formação. Isto se expressa nas concepções de formação de professores presentes nas teses analisadas. Assim como as políticas de formação de professores, a maioria das teses analisadas tem como um dos princípios norteadores da formação, o descarte da teoria, da objetividade e da racionalidade expresso na desqualificação dos conhecimentos clássicos, universais, e em concepções negativas sobre o ato de ensinar. Isto baliza a afirmação do irracionalismo como marca da "contemporaneidade pós-moderna", à luz do qual a construção do conhecimento como forma de decodificação do real em sua universalidade e concretude é negada, (MARTINS, 2010).

\section{Conclusões}

Desde a divisão e a organização burguesa do trabalho, da propriedade privada dos meios de produção, a burguesia vem cuidando para garantir a manutenção de níveis de ignorância da classe trabalhadora, fundamentais para a manutenção da expropriação e da exploração do trabalhador, o que é vital para a manutenção do lucro.

Como vimos no que tange a formação de professores, esta passa a nortear-se pelo descarte da teoria, da objetividade e da racionalidade. Assim contribui-se para a manutenção e o aprofundamento da catástrofe educacional no nosso país, vide os índices educacionais e sobre a formação de professores que não nos deixam mentir. Os jovens da classe trabalhadora chegam no $5^{\circ}, 6^{\circ}, 7^{\circ}$ ano de escolarização sem saber ler, escrever e realizar as operações básicas. Estamos formando gerações e gerações desta maneira, isto em termos históricos, tem/terá um rebatimento sem precedentes na produção e reprodução da vida, na formação humana, pois está se negando aos homens o mínimo para que eles se humanizem. Então, centra-se a educação em paliativos que tratem dos "sintomas", como por exemplo, projetos educativos contra a violência, a discriminação das diferenças, etc, sem atacar o mau pela raiz, o problema em si, que é a desumanização que se dá pela subordinação do trabalho ao capital, pela negação do acesso à riqueza produzida pela humanidade ao conjunto dos homens.

Deste modo, “[...] de pouco ou nada adiantará defender a necessidade de os formadores de professores serem pesquisadores em educação se as pesquisas nessa área se renderem ao 'recuo da teoria' [...]", (DUARTE, 2010, p. 31).

A celebração do "fim da teoria" - movimento que prioriza a eficiência e a construção de um terreno consensual que toma por base a experiência imediata ou o conceito corrente de "prática reflexiva" - se faz acompanhar da promessa de uma utopia alimentada por um indigesto pragmatismo (...). Em tal utopia pragmatista, basta o "saber fazer" e a teoria é considerada perda de tempo ou especulação metafísica e, quando não, restrita a uma oratória persuasiva e fragmentária, presa à sua própria estrutura discursiva. (MORAES, 2001, p. 10)

Afinal, as produções cunhadas a partir deste ceticismo que nega a possibilidade de apreensão da realidade, não contribuem para o enfrentamento dos problemas educacionais do nosso país, haja vista que não consideram suas determinações históricas. Pelo contrário, restringem-se a " [...] relatos ou narrativas que, presas das injunções de uma cultura, acabam por arrimar-se no contingente e na prática imediata - é o que se pode denominar de metafísica do presente [...]", (ibid, p.13). Assim, ao invés de centrarem a formação de professores, em especial dos pedagogos, no estudo profundo das teorias educacionais e 
pedagógicas, da realidade educacional em seus determinantes históricos, permitindo-os explicar teoricamente, e intervir para a alteração da mesma, focalizam a formação nas explicações aparentes, focadas nos sujeitos fragmentários e sua cultura.

Por isto defendemos que uma das tarefas fundamentais para que se avance no campo dos estudos acerca da formação de professores no Brasil é estudá-lo sem perder de vista suas relações e nexos com o modo de produção da existência, vislumbrando uma formação que se contraponha à educação burguesa, unilateral que visa a manutenção do modo de produção capitalista.

\section{Referências}

BRZEZINSKI, I. (org.). Anfope em movimento: 2008-2010. Brasília: Liber Livro: Anfope: Capes, 2011.

BRZEZINSKI, I. Pedagogia, pedagogos e formação de professores: busca e movimento. Campinas, SP: Papirus, 1996.

DUARTE, N. Conhecimento tácito e conhecimento escolar na formação do professor (por que Donald Schön não entendeu Luria). IN: DUARTE, N.; DELLA FONTE, S. Arte, conhecimento e paixão na formação humana: sete ensaios de pedagogia histórico-crítica. Campinas, SP: Autores Associados, 2010.

ENGUITA, M. F. Trabajo, escuela e ideologia. Madrid: Akal/Universitária, 1985.

FREITAS, H. C. L de. Certificação docente e formação do educador: regulação e desprofissionalização. Educação e Sociedade, vol. 24, n. 85, dez. 2003.

Formação de professores no Brasil: 10 anos de embate entre projetos de formação. Campinas: Educação e Sociedade, vol. 23, n. 80, set. 2002.

O trabalho como princípio articulador da teoria/prática: uma análise da prática de ensino e estágios supervisionados na habilitação magistério do curso de pedagogia da FE/UNICAMP. Tese de Doutorado, Faculdade de Educação, Universidade Estadual de Campinas, Campinas-SP, 1993.

FREITAS, L. C de. Crítica da organização do trabalho pedagógico e da didática. Campinas, SP: Papirus, 1995.

FRIGOTTO, G. Educação, crise do trabalho assalariado e do desenvolvimento: teorias em conflito. In: FRIGOTTO, G. (Org.). Educação e crise do trabalho: perspectivas de final de século. Petrópolis, RJ: Vozes, 1998.

HARVEY, D. O neoliberalismo: história e implicações. São Paulo: Edições Loyola, 2008.

MANACORDA, M. A. Marx e a pedagogia moderna. Campinas, SP: Editora Alínea, 2007.

MARTINS, L. M. O legado do século XX para a formação de professores. In: MARTINS, L. M.; DUARTE, N. (orgs.). Formação de professores: limites contemporâneos e alternativas necessárias. São Paulo: Cultura Acadêmica, 2010. 
MORAES, M.C.M. Recuo da teoria: dilemas na pesquisa em educação. Revista Portuguesa de educação, ano/vol. 14, n. 1, pp. 7-25, 2001.

PEIXOTO, E. M. Estudos do lazer no Brasil: apropriação da obra de Marx e Engels. Tese de Doutorado, Faculdade de Educação, Universidade Estadual de Campinas. Campinas, SP: [s.n.], 2007.

PINTO, G. A. A organização do trabalho no século 20: taylorismo, fordismo e toyotismo. São Paulo: Expressão Popular, 2007.

SAVIANI, D. A pedagogia no Brasil: história e teoria. Campinas, SP: Autores Associados, 2008a.

Escola e democracia. Campinas, SP: Autores Associados, 1987.

Pedagogia histórico-crítica: primeiras aproximações. 10. ed. rev. Campinas: Autores Associados, 2008b.

SILVA, C. S. B. da. Curso de pedagogia no Brasil: história e identidade. 2.ed. Campinas, SP: Autores Associados, 2003.

TAFFAREL, C. N. Z. (et al). Currículo. In: UNIVERSIDADE FEDERAL DA BAHIA (UFBA). Cadernos didáticos sobre educação no campo. Salvador, 2009. (no prelo).

Notas

${ }^{1}$ Texto apresentado no painel intitulado Crítica da produção do conhecimento à luz das determinantes do modo de produção: contribuição ao debate da formação de professores em pedagogia e educação do campo do XVI ENDIPE - Encontro Nacional de Didática e Práticas de Ensino - UNICAMP - Campinas - 2012.

${ }^{2}$ PPGE - FACED - UFBA

${ }^{3}$ UFBA

4 Ao realizarmos um levantamento no banco de teses e dissertações da Coordenação de Aperfeiçoamento de Pessoal de Nível Superior (CAPES) e na Biblioteca Digital Brasileira de Teses e Dissertações (BDTD), no período de 1987 a 2010, utilizando os termos de busca 'currículo de pedagogia' e 'currículo do curso de pedagogia'. Baseados no materialismo histórico-dialético analisamos as teses a partir da delimitação das categorias: concepção de homem/formação humana; projeto histórico; escola; trabalho educativo e currículo. As mesmas foram levantadas, sistematizadas, sintetizadas e analisadas - tese a tese -, e seu detalhamento pode ser visto em Gama (2012).

5 Em contraposição à formação unilateral (incompleta, em um único sentido), baseando-se em Marx, Manacorda (2007, p. 87) explica a omnilateralidade como sendo um desenvolvimento total, completo, multilateral, em todos os sentidos, das faculdades, das necessidades e da capacidade da sua satisfação; é considerada objetivamente como o fim da educação. 